\title{
Morbidity and Mortality Associated with Loop Ileostomy Closure Procedures in a Reference Service in Coloproctology in Recife, Pernambuco
}

\section{Morbimortalidade associada aos procedimentos de fechamento de ileostomia em alça em um serviço de referência em coloproctologia em Recife, Pernambuco (PE)}

\author{
Rodrigo Artur Souza de Oliveira ${ }^{1,2(0)}$ Aline Ribeiro Teixeira Cavalcante ${ }^{1,2(0)}$ \\ 1 Sociedade Brasileira de Coloproctologia, Brazil \\ Address for correspondence Rodrigo Artur Souza de Oliveira, Avenida \\ ${ }^{2}$ Coloproctology Service, Hospital Barão de Lucena, Recife, PE. Brazil \\ Caxangá, 3860, Iputinga. Recife (PE), 50731-000, Brazil \\ (e-mail: rodrigoasoliveira@yahoo.com.br).
}

J Coloproctol 2021;41(2):168-175.

\begin{abstract}
Objective To evaluate the morbidity and mortality related to the surgical procedure of loop ileostomy closure, in a reference service in coloproctology, as well as possible variables that may be related to a higher frequency of complications.

Methods A retrospective study evaluated 66 procedures of loop ileostomy closure, performed between December 2005 and December 2017, at the coloproctology service of Barão de Lucena Hospital, in Recife, Brazil.

Results There were complications in 20 (30.3\%) patients, 11 of whom were classified as grade I (Clavien-Dindo), and 9 of whom were classified as grade II to V. In $7.6 \%$ of the cases, one or more surgical reassessments were required. Mortality was $1.5 \%$. There was no statistical relevance in the correlation of the studied variables with the

Keywords

- ileostomy closure

- morbimortality

- Clavien-Dindo

\section{Resumo}

Palavras-chave

- fechamento de ileostomia

- morbimortalidade

- Clavien-Dindo occurrence of complications.

Conclusion Loop ileostomy closure presents an important morbidity, reaching more than $30 \%$, although mortality is low. The analyzed variables did not show significant statistics for a higher occurrence of complications.

Objetivo Avaliar a morbimortalidade relacionada ao procedimento cirúrgico de fechamento ileostomia em alça, em um serviço de referência em coloproctologia, bem como possíveis variáveis que possam se relacionar com uma maior frequência de complicações.

Métodos Estudo retrospectivo, com análise de prontuários de 66 procedimentos de fechamento de ileostomia em alça, realizados entre dezembro de 2005 e dezembro de 2017, no serviço de coloproctologia do Hospital Barão de Lucena, em Recife, PE.

received

April 29, 2020

accepted after revision

January 15, 2021

DOI https://doi.org/

$10.1055 / \mathrm{s}-0041-1730422$

ISSN 2237-9363.

(c) 2021. Sociedade Brasileira de Coloproctologia. All rights reserved.

This is an open access article published by Thieme under the terms of the Creative Commons Attribution-NonDerivative-NonCommercial-License, permitting copying and reproduction so long as the original work is given appropriate credit. Contents may not be used for commercial purposes, or adapted, remixed, transformed or built upon. (https://creativecommons.org/ licenses/by-nc-nd/4.0/)

Thieme Revinter Publicações Ltda., Rua do Matoso 170, Rio de Janeiro, RJ, CEP 20270-135, Brazil
\end{abstract}


Resultados Houve complicações em 20 (30,3\%) pacientes, sendo 11 delas classificadas como grau I (Clavien-Dindo) e 9 classificadas de grau II a V. Em 7,6\% dos casos, houve necessidade de uma ou mais reabordagens cirúrgicas. A mortalidade foi de 1,5\%. Não houve relevância estatística na correlação das variáveis estudadas com a ocorrência de complicações.

Conclusão O procedimento cirúrgico de fechamento de ileostomia apresenta morbidade importante, podendo chegar a mais de 30\%, embora a mortalidade seja baixa. As variáveis analisadas não demonstraram significância estatística para maior ocorrência de complicações.

\section{Introduction}

Loop ileostomy procedures are frequent in surgical practice. This procedure has been used to protect coloanal or colorectal anastomosis in case of low rectal tumors, abdominal trauma with suture or risky anastomosis, extra-peritoneal rectum injuries, and in some cases of complicated diverticular and inflammatory bowel disease, in addition to diversion of intestinal transit in intestinal obstruction in which resection with anastomosis is not feasible. ${ }^{1-3}$

When maintaining anastomosis is an option, loop ileostomy can also be used in re-approaches of patients undergoing colorectal surgery without a protective stoma, who have complications due to leakage. ${ }^{1,2}$

However, the surgical procedure for closing ileostomies can be related to a series of complications, including wall infection, intraperitoneal abscesses, anastomotic fistulas, and intestinal obstructions. Although the mortality rate related to this type of surgery is considered low, in several studies, the global rate of complications can exceed $30 \%$ in some reviews. ${ }^{1,4-7}$

Several variables possibly involved in the triggering of complications related to the procedure to reconstruct the transit are described in the literature, among which we highlight: the surgical technique employed, the time elapsed between the confection and closing of the stoma, the condition that motivated the creation of the ileostomy, the patient's age and general condition, and the use of intestinal preparation or antibiotics. ${ }^{1,3,8}$

Thus, we will evaluate the morbidity and mortality related to the surgical procedure for reversal of loop ileostomies at a reference service in coloproctology in the state of Pernambuco, as well as possible variables that may be related to a higher frequency of complications.

\section{Methods}

The present study was carried out at the coloproctology service of Hospital Barão de Lucena, in Recife, Pernambuco, as a retrospective analysis, which included all patients who underwent ileostomy closure with a peristomal approach from December 2005 to December 2017.

The study excluded patients who required conversion to median laparotomy to close the stoma; patients with stomas other than loop ileostomy; and patients whose medical records were not found.

The study sample consisted of 89 patients, 65 of whom met the inclusion criteria. One of these 65 patients underwent the procedure on two separate occasions, entering the statistical analysis twice, and thus increasing the number of procedures evaluated to 66 .

The data were collected by retrieving medical records, which were analyzed following a preestablished standardized protocol.

Data regarding the epidemiological profile of the patients undergoing the procedure were collected, such as: age, gender, comorbidities, and surgical risk assessment (according to the classification of the American Society of Anesthesiologists- [ASA]).

In addition, we retrieved the following information: initial surgery (in which the stoma was made) and previous diagnosis, highlighting whether the surgery was urgent or elective; complications that occurred in that first procedure; interval between confection and stoma closure; surgical technique used for closure; time until restart of normal diet after transit reconstruction; complications related to this procedure occurring up to the first 30 postoperative days; need for intervention or surgery due to complications; hospital stay until discharge; deaths, if any.

After completing the data collection, we also sought to identify variables that may correlate with a higher frequency of complications from the procedure, assessing: age group, urgency in the stoma-making surgery, complications in the first surgery, time elapsed until the stoma was closed, and surgical technique used to reconstruct the traffic.

Regarding the surgical techniques for closing the ileostomy, the following ones were considered in this study: anastomosis of the anterior wall without enterectomy; segmental resection of the externalized intestinal loop with manual end-to-end anastomosis; side-to-side anastomosis with mechanical suture using a linear stapler.

In the present article, the Clavien-Dindo $\operatorname{score}^{9}(-$ Table 1$)$ was used to classify surgical complications. All complications observed will be described, but two subgroups were also considered for analysis, named minor complications (grade I) and major complications (from grade II of the score on). This subdivision was chosen for statistical purposes, since grade I complications are sometimes resolved with medications 
Table 1 Classification of Clavien-Dindo for surgical complications (original table) ${ }^{9}$

\begin{tabular}{|c|c|}
\hline Grade & Definition \\
\hline Grade I & $\begin{array}{l}\text { - Any deviation from the normal postoperative course without the need for pharmacological treatment or } \\
\text { surgical, endoscopic, and radiological interventions } \\
\text { - Allowed therapeutic regimens are drugs as antiemetics, antipyretics, analgetics, diuretics, electrolytes, } \\
\text { and physiotherapy. This grade also includes wound infections opened at the bedside }\end{array}$ \\
\hline Grade II & $\begin{array}{l}\text { - Requiring pharmacological treatment with drugs other than such allowed for grade I complications } \\
\text { - } \text { Blood transfusions and total parenteral nutrition are also included }\end{array}$ \\
\hline Grade III & $\begin{array}{l}\text { - Requiring surgical, endoscopic, or radiological intervention } \\
\text { Illa. Intervention not under general anesthesia } \\
\text { Illb. Intervention under general anesthesia }\end{array}$ \\
\hline Grade IV & $\begin{array}{l}\text { - } \text { Life-threatening complication (including CNS complications)* } \\
\text { - } \text { requiring IC/ICU management } \\
\text { IVa. Single organ dysfunction (including dialysis) } \\
\text { IVb. Multiorgan dysfunction }\end{array}$ \\
\hline Grade V & Death of a patient \\
\hline Suffix “d” & $\begin{array}{l}\text { If the patient suffers from a complication at the time of discharge (see examples in Table } 2 \text { ), the suffix "d" (for } \\
\text { "disability") is added to the respective grade of complication. This label indicates the need for a follow-up to } \\
\text { fully evaluate the complication }\end{array}$ \\
\hline
\end{tabular}

Abbreviations: CNS, central nervous system; IC, intermediate care; ICU, intensive care unit.

*Brain hemorrhage, ischemic stroke, subarrachnoidal bleeding, but excluding transient ischemic attacks.

commonly used in the postoperative period, such as analgesics and antiemetics, and no further intervention is necessary.

To assess the significance of the analysis of variables, the data were expressed through absolute and percentage frequencies for categorical variables and statistical measures. The Fisher exact test was used to compare the groups in relation to the categorical variables, since the condition for using the chi-square test was not verified.

The margin of error used in the decisions of the statistical tests was $5 \%$. The data were tabulated in an Excel spreadsheet and the IBM SPSS Statistics for Windows, Version 23.0 software (IBM Corp., Armonk, NY, USA) was used to obtain statistical calculations.

The project was submitted to the research ethics committee of Hospital Agamenon Magalhães, in Recife (PE), as recommended by CONEP (National Research Ethics Committee). It was approved on July 28, 2017, under the Certificate of Presentation for Ethical Appreciation (Certificado de Apresentação para Apreciação Ética - CAAE) number 68079717.0.0000.5197, and the opinion number $2,191,360$.

\section{Results}

Sixty-six loop ileostomy closure procedures were analyzed, and the patients' characteristics are shown in - Table 2.

Regarding gender, 34 (51.5\%) cases were female. The patients' age ranged from 17 to 81 years old, with an average of 55.5. Most patients were classified as ASA I or ASA II for assigned surgical risk, each corresponding to $48.5 \%$ of the sample, and the remaining $3 \%$ were classified as ASA III.
Table 2 Evaluation of the baseline characteristics of the patients analyzed

\begin{tabular}{|l|c|}
\hline Variable & Result \\
\hline TOTAL: $\mathbf{n}(\%)$ & $66(100.0)$ \\
\hline Age: Average \pm SD (Median) & $\begin{array}{c}53.92 \pm 15.66 \\
(55.50)\end{array}$ \\
\hline Age group (years old): $\mathrm{n}(\%)$ & \\
\hline $17-64$ & $46(69.7)$ \\
\hline $65-81$ & $20(30.3)$ \\
\hline Gender: $\mathrm{n}(\%)$ & \\
\hline Male & $32(48.5)$ \\
\hline Female & $34(51.5)$ \\
\hline ASA: $\mathrm{n}$ (\%) & \\
\hline I & $32(48.5)$ \\
\hline II & $32(48.5)$ \\
\hline III & $2(3.0)$ \\
\hline Presence of comorbidities: $\mathrm{n}(\%)$ & $32(48.5)$ \\
\hline Which comorbidities**: $\mathrm{n}(\%)$ & \\
\hline None & $34(51.5)$ \\
\hline Systemic arterial hypertension & $19(28.8)$ \\
\hline Inflammatory bowel disease & $5(7.6)$ \\
\hline Diabetes mellitus & $4(6.0)$ \\
\hline COPD & $2(3.0)$ \\
\hline Others & $14(21.2)$ \\
\hline
\end{tabular}

Abbreviations: COPD, chronic obstructive pulmonary disease; SD, standard deviation. 


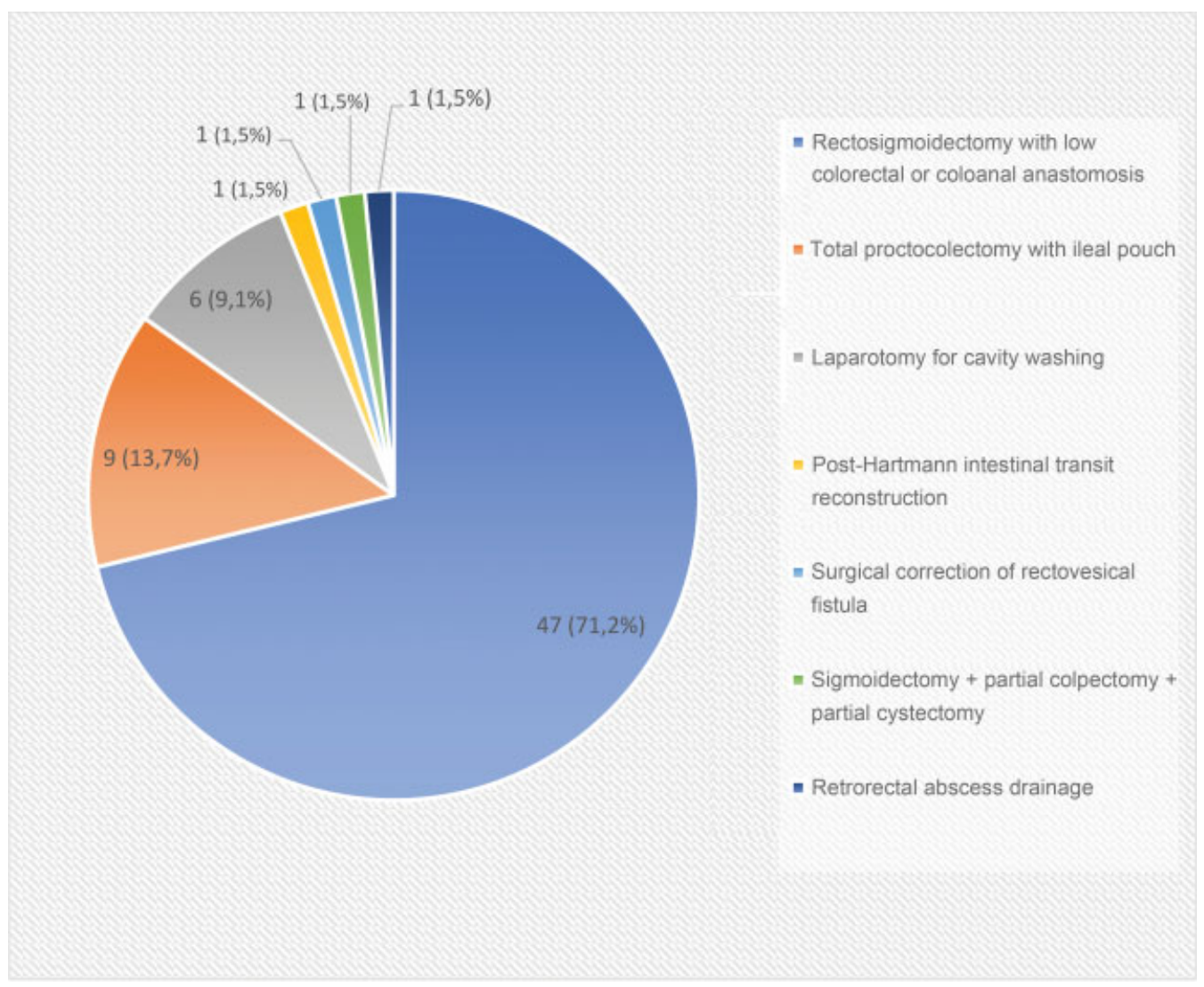

Graph 1 Division regarding the surgical procedure performed when making the ileostomy.

The presence of comorbidities was registered in 32 patients (48.5\%), highlighting systemic arterial hypertension, present in $28.8 \%$ of cases.

As shown in Graph 1, at the initial surgery, most patients (71.2\%) underwent rectosigmoidectomy with low colorectal or coloanal anastomosis. Total proctocolectomy with the creation of an ileal pouch was performed on 9 occasions (13.7\%). Urgent procedures were performed 7 times (10.6\%), with 6 exploratory laparotomies with a cavity washing and one retrorectal abscess drainage.

In Graph 2, regarding the underlying disease, rectal adenocarcinoma or tumor recurrence were recorded in 47 patients (71.2\%). Familial adenomatous polyposis (6.1\%), inflammatory bowel disease (7.6\%), and cases of urgent procedures for anastomotic dehiscence $(7.6 \%)$ were also highlighted.

Complications in the first procedure were recorded in $33.3 \%$ of the patients, and surgical reintervention was necessary on 13 occasions.

Regarding complications related to the ostomy, only 5 (7.6\%) cases were registered in the medical records: 3 (4.5\%) cases of parastomal hernia and $2(3.1 \%)$ cases of ileostomy prolapse. The average time to ostomy closure was 9.71 months; in most of the cases (63.6\%), the interval until the procedure was equal to or greater than 7 months.

Regarding the surgical techniques used, manual enterorrhaphy without an enterectomy was performed in $39.4 \%$ of the cases; segmental enterectomy with manual end-to-end enteroanastomosis in 37.9\%; and mechanical anastomosis using a linear stapler in $21.2 \%$. In one of the medical records, the surgical description was not found.

The time to restart normal diet was 1 day (1st postoperative) in $69.7 \%$ of patients.

The data related to ileostomy closure procedures are described in - Table 3.

When analyzing globally (grade I-V, using the ClavienDindo score ${ }^{9}$ ), there were complications in 20 (30.3\%) patients, 11 of which were classified as grade I.

In two (3\%) patients included in grade I of the ClavienDindo score, ${ }^{9}$ readmission after discharge was necessary, both due to intestinal subocclusion treated only with clinical procedures, and criteria for grade II of the score were not established.

Nine (13.6\%) patients developed major early complications (grade II-V by Clavien Dindo ${ }^{9}$ ), and, in 5 (7.6\%) cases, one or more surgical approaches were necessary.

Of the 5 patients who needed a re-approach, $4(6 \%)$ presented anastomotic dehiscence. Of these four, two had an associated intracavitary abscess, and in one of them, the anastomosis dehiscence had been precipitated by intestinal obstruction due to internal hernia; this same patient later eviscerated. The fifth patient who underwent new surgery had pain and abdominal distension due to anastomosis stenosis.

All reoperated patients underwent a new ostomy.

The average time for manifestaion of symptoms in patients who evolved with dehiscence of anastomosis was 2.75 days, with the 1 st re-approach occurring on 


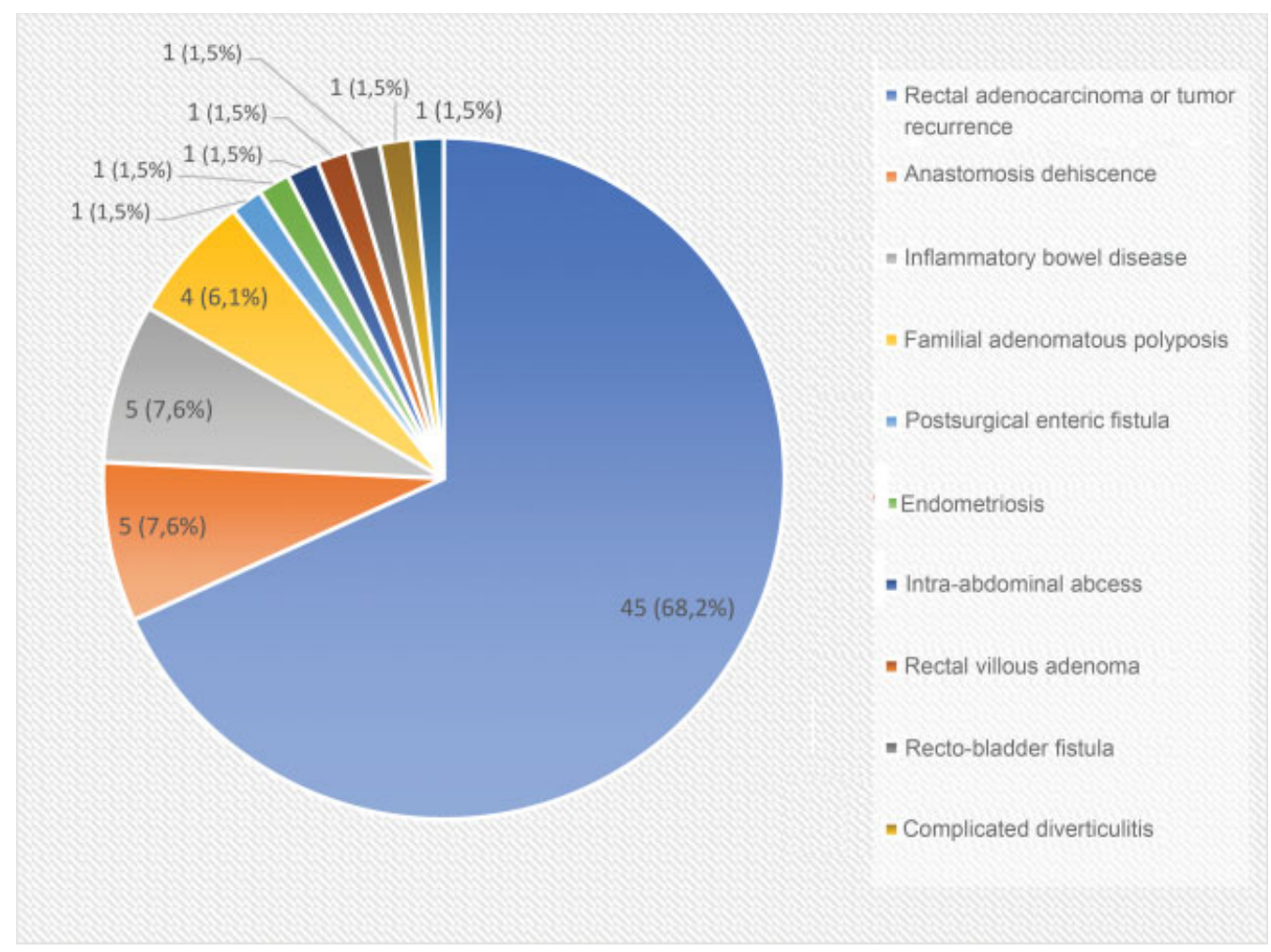

Graph 2 Division regarding the underlying disease that resulted in the surgery of ileostomy.

Table 3 Evaluation of variables related to the surgical ileostomy closure procedure

\begin{tabular}{|l|c|}
\hline Variable & Total group \\
\hline TOTAL: $\mathbf{n}(\%)$ & $66(100.0)$ \\
\hline $\begin{array}{l}\text { Time to ostomy closure (months): Average } \pm \text { SD } \\
\text { (Median) }\end{array}$ & $\begin{array}{c}9.71 \pm 6.72 \\
(8.00)\end{array}$ \\
\hline Time to ostomy closure: $\mathrm{n}(\%)$ & \\
\hline Less than 7 months & $24(36.4)$ \\
\hline 7 months or more & $42(63.6)$ \\
\hline Surgical technique used to close ileostomy: $\mathrm{n}(\%)$ & \\
\hline Manual without enterectomy & $26(39.4)$ \\
\hline Manual with enterectomy & $25(37.9)$ \\
\hline Mechanical & $14(21.2)$ \\
\hline No mention in the medical record & $1(1.5)$ \\
\hline $\begin{array}{l}\text { Early complication after ileostomy closure }- \\
\text { Clavien-Dindo I to V: } \mathrm{n}(\%)\end{array}$ & $20(30.3)$ \\
\hline Clavien-Dindo I & $11(16.7)$ \\
\hline Clavien-Dindo II-V & $9(13.6)$ \\
\hline $\begin{array}{l}\text { Time to discharge, in days (without complications } \\
\text { and Clavien-Dindo I): Average } \pm \text { SD (Median) }\end{array}$ & $4.35 \pm 1.54$ \\
\hline $\begin{array}{l}\text { Time to discharge, in days (Clavien-Dindo II-V) }{ }^{* *}: \\
\text { Average } \pm \text { SD (Median) }\end{array}$ & $\begin{array}{r}(22.00) \\
\hline \text { Time to discharge* }: \mathrm{n} \text { (\%) }\end{array}$ \\
\hline Less than 5 days & $35(53.0)$ \\
\hline 5 days & $15(22.7)$ \\
\hline More than 5 days & $14(21.2)$ \\
\hline
\end{tabular}

Abbreviation: SD, standard deviation.

*This statistic excluded the patient who died and the one without data in the medical record. average on the 5 th postoperative day. The patient who evolved with anastomosis stenosis started presenting symptoms around the 3rd postoperative day and was reoperated on the 17 th day. Abdominal pain and distension were the most frequent symptoms reported in these patients.

A single case of death was reported: after prolonged hospitalization for adynamic ileus, it evolved to a septic shock with pulmonary focus, and death on the 24th postoperative day.

- Table 4 shows the complications and the respective classification in the Clavien-Dindo score. ${ }^{9}$

The average time to hospital discharge in the group without complications or with minor complications (Clavien-Dindo ${ }^{9}$ grade I) was 4.35 days, with a median of 4 days, with $75.7 \%$ of the total patients being discharged in 5 days or less. When analyzing only patients who evolved with major complications (except for death and one patient who did not report discharge in the medical record), time until discharge rises to 20.14 days.

- Table 5 shows the results of crossing the occurrence of complications with the characterization and clinical variables. For the fixed error margin (5\%), there was no statistically significant association $(p<0.05)$ for any of the variables analyzed.

\section{Discussion}

The expansion of the indications for the use of loop ileostomy enabled a better observation and analysis of complications related to its construction and closure. ${ }^{1,4}$ 
Table 4 Early complications after closure of ileostomy

\begin{tabular}{|l|l|l|}
\hline Variable & Total group & $\begin{array}{l}\text { Clavien- } \\
\text { Dindo }\end{array}$ \\
\hline TOTAL PATIENTS: $\mathbf{n}(\%)$ & $66(100.0)$ & \\
\hline Which complications ${ }^{*}$ n (\%) & & \\
\hline Vomiting & $5(7.6 \%)$ & $\mathrm{I}$ \\
\hline Anastomosis dehiscence (surgical) & $4(6 \%)$ & $\mathrm{IIIb}$ \\
\hline $\begin{array}{l}\text { adynamic ileum (02 using TPN and } \\
01 \text { using antibiotics - secondary to } \\
\text { pulmonary infection) }\end{array}$ & $3(4.6 \%)$ & $\mathrm{II}$ \\
\hline Pneumonia & $2(3 \%)$ & $\mathrm{II}$ \\
\hline $\begin{array}{l}\text { Surgical wound infection } \\
\text { (without antibiotics) }\end{array}$ & $2(3 \%)$ & $\mathrm{I}$ \\
\hline $\begin{array}{l}\text { Intestinal subocclusion } \\
\text { (with clinical resolution) }\end{array}$ & $2(3 \%)$ & $\mathrm{I}$ \\
\hline Intracavitary abscess (surgical) & $2(3 \%)$ & $\mathrm{IIIb}$ \\
\hline $\begin{array}{l}\text { Intracavitary abscess } \\
\text { (percutaneous drainage) }\end{array}$ & $1(1.5 \%)$ & $\mathrm{IIla}$ \\
\hline Internal hernia & $1(1.5 \%)$ & $\mathrm{IIIb}$ \\
\hline Evisceration & $1(1.5 \%)$ & $\mathrm{IIIb}$ \\
\hline Anastomosis stenosis & $1(1.5 \%)$ & $\mathrm{IIIb}$ \\
\hline Abscess of abdominal wall & $1(1.5 \%)$ & $\mathrm{II}$ \\
\hline Enterocutaneous fistula & $1(1.5 \%)$ & $\mathrm{II}$ \\
\hline $\begin{array}{l}\text { Surgical wound infection } \\
\text { (using antibiotics) }\end{array}$ & $1(1.5 \%)$ & $\mathrm{II}$ \\
\hline Diarrhea (using antibiotics) & $1(1.5 \%)$ & $\mathrm{II}$ \\
\hline Fever & $1(1.5 \%)$ & $\mathrm{I}$ \\
\hline Operative wound seroma & $1(1.5 \%)$ & $\mathrm{I}$ \\
\hline Headache & $1(1.5 \%)$ & $\mathrm{I}$ \\
\hline Septic shock & $1(1.5 \%)$ & $\mathrm{IVb}$ \\
\hline Death & $1(1.5 \%)$ & $\mathrm{V}$ \\
\hline
\end{tabular}

*Each patient may have more than one complication.

Although it is sometimes considered a less complex procedure, it does require care and attention, both in surgical indication and in anastomosis for reversion, which can be related to a high rate of morbidity, and even mortality. ${ }^{1,4-6}$

In this study, a general complication rate of $30.3 \%$ (grade IV) was observed, above that observed in meta-analysis studies, such as those by Chow et al. ${ }^{4}$ (which analyzed 6,107 cases) and Sharma et al. ${ }^{8}$ (with a total of 5,401 patients evaluated), with rates of $17.28 \%$ and $17.66 \%$, respectively. In a Brazilian study ${ }^{10}$ carried out in the state of São Paulo with 93 patients, the overall rate of complications was $17.2 \%$. In studies carried out in Madrid and Murcia (Spain) with 89 patients, these percentages were even higher: $40.8 \%{ }^{6}$ and $45.8 \%$, respectively.$^{11}$ The overall complication rate in most articles ranges from 10 to $17 \%$ and may reach over $30 \%$ in some reviews. ${ }^{1,4-7}$

The definition and division of surgical complications into groups varies widely in the literature, which is a limiting factor when comparing the data. In the present review, 13.6\% of complications were considered major (grade II-V by Clavien Dindo ${ }^{9}$ ). Rubio-Perez et al. ${ }^{6}$ used the same score, and observed an $18.27 \%$ rate of complications, in the same mentioned grades. Sharma et al. ${ }^{8}$, on the other hand, refer to the term major complications when they include intracavitary infections, organ failure, need for reoperation, pneumonia, cardiac events, and venous thromboembolism, among others, with $9.3 \%$ of patients included in this group. In a Swedish study, ${ }^{12}$ the complications considered major were those classified from grade IIIB of Clavien-Dindo, ${ }^{9}$ corresponding to $8.2 \%$ of the total.

There was a need for reoperation in $5(7.6 \%)$ cases, and, in 4 (6\%) of them, there was anastomotic dehiscence, while the other reoperation occurred due to anastomosis stenosis. A Danish study ${ }^{7}$ carried out in Copenhagen found a $17 \%$ rate of reoperations, with $2.53 \%$ of the patients with anastomotic dehiscence and 3.1\% having been reopened due to intestinal obstruction. Mengual et al. ${ }^{11}$ showed a lower value, 3.37\%, of need for surgical reintervention, a similar value to that found by Perez et al., ${ }^{10}$ in São Paulo, with 3.2\% of reoperation and $1.07 \%$ of the total cases with anastomosis dehiscence. In the meta-analysis by Chow et al., ${ }^{4}$ the anastomosis dehiscence rate was $1.4 \%$.

In the present study, a new ostomy was made in the five cases submitted to reoperation. In a study by van Westreenen et al. ${ }^{13}$ with 138 patients, 8 of the 11 (72.7\%) reapproached patients also needed a new stoma. Perez et al. ${ }^{10}$ reported 3 re-approaches in their study, none requiring ostomy. They highlighted a case of anastomosis dehiscence in which enterectomy and reanastomosis were performed with good evolution, demonstrating that this may be a possible approach in some cases.

Regarding mortality, there was a single death reported in this review (1.5\%). In two meta-analyses studied, the mortality rate was $0.4 \%{ }^{4}$ and $0.6 \% .{ }^{8}$ In some institutional studies, with similar design and number of patients, there were no reported deaths. ${ }^{7,14}$

The average time to discharge was higher in the group with major complications than in patients without complications or grade I complications: 20.14 days and 4.35 days, respectively. This difference was also reported by MengualBallester et al., ${ }^{11}$ the group without complications remained on average for 4.58 days, while the group with complications had a stay of 11 days. In general, the average length of stay in the studies ranged from 4 to 6.8 days. $3,4,7,10,13,14$

Some variables and their possible relationships with a higher incidence of complications were also evaluated with no statistical significance found in any of them in the present study. This fact may be due to the limited number of patients analyzed, suggesting the need for reviews that include a larger number of patients, which are still few in the literature.

The time interval between the preparation and the closure of the ileostomy remains a controversial topic, with no consensus in the literature of the ideal time to perform the reconstitution of intestinal transit. ${ }^{1,6,11,14,15}$ In this review, this interval was equal to or greater than 7 months in $63.6 \%$ of cases.

Some authors advocate the possibility of early closure of the stoma, even during the same hospitalization, if there is no clinical, radiological or endoscopic evidence of leak in the anastomosis. $^{16,17}$ In any case, late closure of the stoma 
174 Morbidity and Mortality Associated with Loop Ileostomy Closure Procedures Oliveira, Cavalcante

Table 5 Assessment of the occurrence of complications (grade II-V of Clavien-Dindo ${ }^{9}$ ), according to specific variables

\begin{tabular}{|c|c|c|c|c|c|c|c|}
\hline \multirow{3}{*}{ Variable } & \multicolumn{4}{|c|}{ Complication } & & & \multirow{3}{*}{$P$-value } \\
\hline & \multicolumn{2}{|c|}{ With } & \multicolumn{2}{|c|}{ Without } & \multicolumn{2}{|c|}{ Total } & \\
\hline & $\mathrm{N}$ & $\%$ & $\mathrm{~N}$ & $\%$ & $\mathrm{n}$ & $\%$ & \\
\hline Age group & & & & & & & $p^{*}=0.437$ \\
\hline $65-81$ & 4 & 20.0 & 16 & 80.0 & 20 & 100.0 & \\
\hline $17-64$ & 5 & 10.9 & 41 & 89.1 & 46 & 100.0 & \\
\hline Total group & 9 & 13.6 & 57 & 86.4 & 66 & 100.0 & \\
\hline First emergency surgery & & & & & & & $p^{*}=0.581$ \\
\hline Yes & - & - & 7 & 100.0 & 7 & 100.0 & \\
\hline No & 9 & 15.3 & 50 & 84.7 & 59 & 100.0 & \\
\hline Total group & 9 & 13.6 & 57 & 86.4 & 66 & 100.0 & \\
\hline Complications in the first surgery & & & & & & & $p^{*}=0.705$ \\
\hline Yes & 4 & 15.4 & 22 & 84.6 & 26 & 100.0 & \\
\hline No & 4 & 10.5 & 34 & 89.5 & 38 & 100.0 & \\
\hline Total group & 8 & 12.5 & 56 & 87.5 & 64 & 100.0 & \\
\hline Time to ostomy closure & & & & & & & $p^{*}=0.469$ \\
\hline Less than 7 months & 2 & 8.3 & 22 & 91.7 & 24 & 100.0 & \\
\hline Equal to or greater than 7 months & 7 & 16.7 & 35 & 83.3 & 42 & 100.0 & \\
\hline Total group & 9 & 13.6 & 57 & 86.4 & 66 & 100.0 & \\
\hline Type of anastomosis & & & & & & & $p^{*}=0.625$ \\
\hline Manual without enterectomy & 2 & 7.7 & 24 & 92.3 & 26 & 100.0 & \\
\hline Manual with enterectomy & 4 & 16.0 & 21 & 84.0 & 25 & 100.0 & \\
\hline Mechanical & 2 & 14.3 & 12 & 85.7 & 14 & 100.0 & \\
\hline Total group & 8 & 12.3 & 57 & 87.7 & 65 & 100.0 & \\
\hline
\end{tabular}

*B Fy Fisher Exact test.

remains with different studies reporting ideal average time between 8 weeks to 6 months. ${ }^{6,11,14,15}$

Another point of discussion refers to the type of anastomosis performed, whether manual (with or without enterectomy) or mechanical (using a linear stapler). In the present article, there was no statistically significant difference regarding the occurrence of complications when comparing the 3 techniques reported. Other institutional studies, such as those by Perez et al. ${ }^{10}$ and van Westreenen et al., ${ }^{13}$ also showed no difference.

A recent meta-analysis ${ }^{18}$ published in 2015 reviewed 4 randomized trials on the subject and concluded that there was strong evidence that mechanical anastomoses had lower rates of intestinal obstruction and shorter surgical time, in addition to shorter time of hospitalization when compared to manual anastomoses, but there was no significant difference when comparing anastomotic dehiscence. These data were corroborated by other meta-analyses, such as those by de Gong et al. ${ }^{19}$ and Markides et al. ${ }^{20}$

\section{Conclusion}

The surgical procedure for ileostomy closure has important morbidity, and this should be analyzed when indicating it.
The analyzed variables did not show statistical significance for a higher occurrence of complications.

Conflict of interests

The authors declare that there is no conflict of interests.

\section{References}

1 Seid VE. Resultados imediatos do fechamento de ileostomia em alça [dissertação]. São Paulo: Faculdade de Medicina, Universidade de São Paulo; 2004:201p

2 Musters GD, Atema JJ, van Westreenen HL, Buskens CJ, Bemelman WA, Tanis PJ. Ileostomy closure by colorectal surgeons results in less major morbidity: results from an institutional change in practice and awareness. Int J Colorectal Dis 2016;31 (03):661-667

3 Oliveira RAN, Oliveira PG, Nobrega dos Santos AC, de Sousa JB. Morbidade e mortalidade associadas ao fechamento de colostomias e ileostomias em alça acessadas pelo estoma intestinal. Rev Col Bras Cir 2012;39(05):389-393

4 Chow A, Tilney HS, Paraskeva P, Jeyarajah S, Zacharakis E, Purkayastha $S$. The morbidity surrounding reversal of defunctioning ileostomies: a systematic review of 48 studies including 6,107 cases. Int J Colorectal Dis 2009;24(06):711-723

5 Poskus E, Kildusis E, Smolskas E, Ambrazevicius M, Strupas K. Complications after loop ileostomy closure: a retrospective analysis of 132 patients. Viszeralmedizin 2014;30(04):276-280 
6 Rubio-Perez I, Leon M, Pastor D, Diaz Dominguez J, Cantero R. Increased postoperative complications after protective ileostomy closure delay: An institutional study. World J Gastrointest Surg 2014;6(09):169-174

7 El-Hussuna A, Lauritsen M, Bülow S. Relatively high incidence of complications after loop ileostomy reversal. Dan Med J 2012;59 (10):A4517

8 Sharma A, Deeb AP, Rickles AS, Iannuzzi JC, Monson JRT, Fleming FJ. Closure of defunctioning loop ileostomy is associated with considerable morbidity. Colorectal Dis 2013;15(04):458-462

9 Dindo D, Demartines N, Clavien PA. Classification of surgical complications: a new proposal with evaluation in a cohort of 6336 patients and results of a survey. Ann Surg 2004;240(02):205-213

10 Perez RO, Habr-Gama A, Seid VE, et al. Loop ileostomy morbidity: timing of closure matters. Dis Colon Rectum 2006;49(10):1539-1545

11 Mengual-Ballester M, García-Marín JÁ, Pellicer-Franco E, et al. Protective ileostomy: complications and mortality associated with its closure. Rev Esp Enferm Dig 2012;104(07):350-354

12 Holmgren K, Kverneng Hultberg D, Haapamäki MM, Matthiessen P, Rutegård J, Rutegård M. High stoma prevalence and stoma reversal complications following anterior resection for rectal cancer: a population-based multicentre study. Colorectal Dis 2017;19(12):1067-1075

13 van Westreenen HL, Visser A, Tanis PJ, Bemelman WA. Morbidity related to defunctioning ileostomy closure after ileal pouch-anal anastomosis and low colonic anastomosis. Int J Colorectal Dis 2012;27(01):49-54
14 Waterland P, Goonetilleke K, Naumann DN, Sutcliff M, Soliman F. Defunctioning ileostomy reversal rates and reasons for delayed reversal: does delay impact on complications of ileostomy reversal? A study of 170 defunctioning ileostomies. J Clin Med Res 2015;7(09):685-689

15 Zhen L, Wang Y, Zhang Z, et al. Effectiveness between early and late temporary ileostomy closure in patients with rectal cancer: A prospective study. Curr Probl Cancer 2017;41(03):231-240

16 Alves A, Panis Y, Lelong B, Dousset B, Benoist S, Vicaut E. Randomized clinical trial of early versus delayed temporary stoma closure after proctectomy. Br J Surg 2008;95(06): 693-698

17 Danielsen AK, Park J, Jansen JE, et al. Early closure of a temporary ileostomy in patients with rectal cancer - A multicenter randomized controlled trial. Ann Surg 2017;265(02):284-290

18 Löffler T, Rossion I, Gooßen K, et al. Hand suture versus stapler for closure of loop ileostomy-a systematic review and meta-analysis of randomized controlled trials. Langenbecks Arch Surg 2015;400 (02):193-205

19 Gong J, Guo Z, Li Y, et al. Stapled vs hand suture closure of loop ileostomy: a meta-analysis. Colorectal Dis 2013;15(10): e561-e568

20 Markides GA, Wijetunga IU, Brown SR, Anwar S. Meta-analysis of handsewn versus stapled reversal of loop ileostomy. ANZ J Surg 2015;85(04):217-224 